\title{
An Inventory and Engineering Assessment of Flared Gas and Liquid Waste Streams From Hydraulic Fracturing in the USA
}

\author{
Yael R. Glazer $^{1} \cdot$ F. Todd Davidson ${ }^{1} \cdot$ Jamie J. Lee $^{2} \cdot$ Michael E. Webber $^{1}$
}

Published online: 30 October 2017

(C) The Author(s) 2017. This article is an open access publication

\begin{abstract}
Purpose of Review In this study, we compile and curate data from 2012, 2013, and 2014 on flared gas and generated wastewater associated with hydraulic fracturing operations in seven major shale regions of the USA. In the process, we provide an historical perspective of the management practices of flared gas and wastewater prior to the decline in oil prices in 2015 . An engineering assessment of the technical potential for repurposing the energy from flared gas for treating hydraulic fracturing wastewater is also considered.

Recent Findings The seven shale regions were evaluated using mass balances and thermodynamic analysis of the wastewater and flared gas volumes using data compiled from state, federal, and private sources for each region. After curating the publicly available data, we determined that from 2012 through 2014, the Bakken, Marcellus, Utica, and Niobrara flared between 2 and 48 times the amount of natural gas needed to provide energy for treatment of the wastewater produced from the oil and gas industry. The Permian Basin, Eagle Ford, and Haynesville did not have sufficient flared gas to treat the wastewater produced in each respective region and thus would need other energy sources for water and wastewater treatment. Summary The findings indicate that novel approaches to managing existing resources and waste streams might have the
\end{abstract}

This article is part of the Topical Collection on Environmental Issues in Oil and Gas Production

Yael R. Glazer

yael@utexas.edu

1 The University of Texas at Austin, 204 E. Dean Keeton St. Stop C2200, Austin, TX 78712, USA

2 University of Chicago, Chicago, IL, USA potential to improve the environmental footprint and economic productivity of select oil and gas sites.

Keywords Hydraulic fracturing · Natural gas · Flared gas · Wastewater $\cdot$ Produced water $\cdot$ Shale $\cdot$ Water treatment
Abbreviation
FG Flared Gas
HF Hydraulic Fracturing
WW Wastewater
TW Treated Water
SWD Saltwater Disposal

\section{Introduction}

The USA has seen significant increases to its domestic oil and natural gas production since 2008 due in large part to the rise in hydraulic fracturing (HF) and horizontal drilling activity [1]. Improvements in these unconventional well completion techniques have helped make extraction from shale deposits economical.

Unconventional oil and gas well completion and production are often accompanied by two major waste streams: generated wastewater (WW) and associated natural gas flaring (both the energy potential lost and emissions resulting from flaring yields a waste of resources). Along with the significant water required for well completion, these are the most prominent environmental liabilities often associated with HF. While all three environmental challenges (significant water use, flaring, and wastewater generation) are present in most shale regions, their impact and severity on a regional and local level depend on a variety of factors including the geology of the shale formations, prevailing climate conditions, access to freshwater resources, access to 
nearby saltwater disposal (SWD) sites, existing pipeline infrastructure, and state regulations, among other factors.

Typically $8,000-50,000 \mathrm{~m}^{3}$ (2-13 million gallons) of water (often freshwater) are mixed with sand and chemicals to create a fracturing fluid that is injected into the well during the HF process [2]. Drilling of longer laterals has become more commonplace and has resulted in a growing amount of water use per well for HF [3]. Some percentage of that fluid will return to the surface during completion as flowback water. In addition, water naturally occurring in the formation, termed produced water, will return to the surface along with the oil and gas over the lifetime of the well. Flowback and produced water along with drilling muds make up the WW generated from unconventional well drilling, completions, and operations that need to be managed. In regions where both oil and gas are produced, operators will sometimes flare some portion of the produced associated natural gas on-site rather than venting it or delivering it to market. Flaring natural gas can be the response to varying spatial and temporal conditions including changes in well conditions that might create a safety hazard or the lack of sufficient natural gas gathering and transmission infrastructure.

To the author's knowledge, no prior work in the archival literature compiles and curates both the volumes of WW and flared gas (FG) by shale region in the USA into an integrated study. This work seeks to fill that gap as understanding the volumes associated with these two waste streams and how they vary by region can help reveal the magnitude of the challenge to managing and mitigating HF's environmental liabilities. In addition, we investigate whether sufficient energy was flared during the years 2012 through 2014 to treat the generated WW in each respective region. If the FG was repurposed as a source of energy for WW treatment, then the volume of WW requiring disposal could have been reduced, the natural gas that would otherwise be wasted could have been put to beneficial use, and treated water (TW) could be generated that can then be reused for beneficial purposes, thereby solving multiple problems simultaneously. Our previous study used extensive datasets and engineering models to assess the potential to use the energy from FG for on-site treatment of HF WW in Texas and concluded that in 2012, Texas flared enough natural gas to generate 180 540 million $\mathrm{m}^{3}$ (46-140 billion gallons) of TW, representing $1-2.4 \%$ of total statewide water demand for all purposes [4]. These results, along with the knowledge that many operators in shale regions across the U.S. grapple with these environmental issues, motivated the expansion of this work to evaluate waste streams associated with HF on a national level for multiple major shale regions.

\section{Operating Procedures}

While well completion techniques, water acquisition, and WW management practices often vary by region, there are many aspects that remain relatively consistent across the country, including the following: the majority of water necessary for well completions is sourced from nearby surface water or groundwater, the bulk of WW is disposed of via SWD, and in areas where gas gathering infrastructure is lacking or insufficient, large volumes of the associated natural gas are flared [5]. There are notable exceptions to these commonalities, such as the relative infrequency of SWD in Pennsylvania [6].

Furthermore, a growing percentage of the WW is treated and reused in many shale regions [7]. Additionally, new regulations are scheduled to limit natural gas flaring in regions like the Bakken, leading operators to capture the associated natural gas [8]. In light of these trends, the approach analyzed here could help mitigate continued flaring of associated gas, extensive water sourcing, and WW disposal.

This study closely examines the years prior to the significant drop in oil prices around 2015. The dramatic decline in oil prices changed many operating practices in the oil and gas field that led to decreased volumes of FG as the rig count declined in some regions (e.g., in the Bakken Formation in North Dakota) as well as potential increases in water injection volumes per well as longer laterals were used to increase productivity on a per well basis (e.g., in the Permian Basin in west Texas). Despite changes since 2015, the waste streams of FG and WW remain significant; this work intends to provide historical context for future operations by investigating FG and WW production over the period of 2012 to 2014.

\section{Shale Regions of Interest}

Seven shale regions representing the vast majority of growth in oil and gas operations in the USA during the decade leading up to 2015 were chosen for this study: Permian Basin, Eagle Ford, Haynesville, Marcellus, Utica, Niobrara, and Bakken (Fig. 1). Together, these regions made up 56\% of total oil production and $50 \%$ of total natural gas production in the USA in 2015 and made up more than $90 \%$ of new growth in oil and gas production in the USA between 2011 and 2014 [9]. The Permian Basin, Eagle Ford, and Bakken are key regions for shale oil production, having produced 20,17, and $13 \%$ of total domestic oil production in 2015 , respectively. The Marcellus is the dominant shale gas producer, having extracted an average of 480 million $\mathrm{m}^{3} /$ day $(16,800$ million cubic feet/day) of natural gas in 2015, the equivalent of almost $19 \%$ of total domestic gas production [9].

\section{Unique Attributes of Shale Regions}

Each shale region presents its own unique challenges based on a variety of factors, including differences in formation 


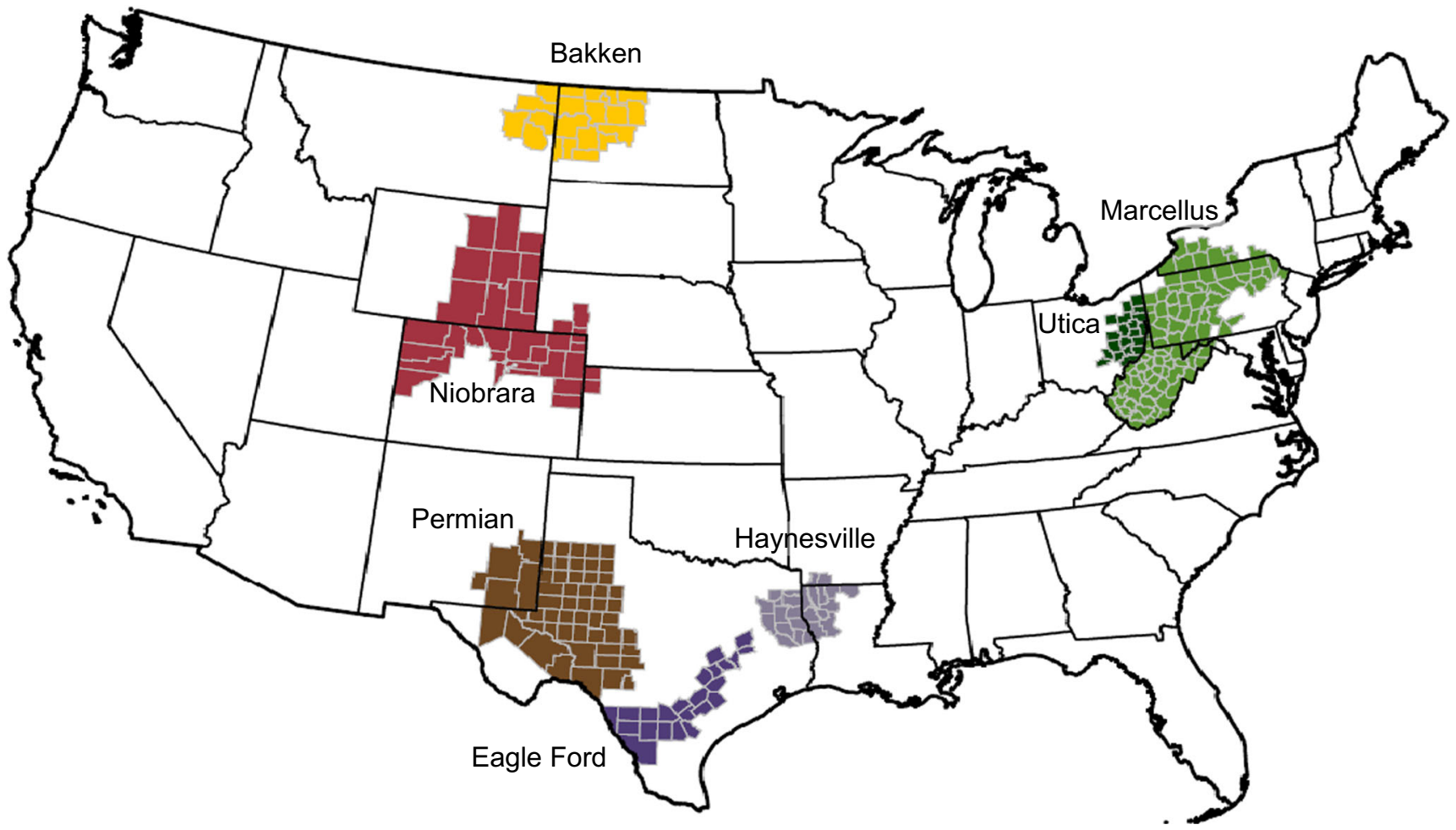

Fig. 1 A map from the EIA Drilling Productivity Report showing the locations of the seven shale plays investigated in this study [39]

geology, local water availability, WW management challenges, FG volumes, and local regulations, to name a few. Variations in geology from one region to the next result in differences in water requirements for well completion and production [10], and varying quantities and qualities of the subsequent generated WW. For example, as of 2011, wells hydraulically fractured in the Niobrara required an average of $12,500 \mathrm{~m}^{3}$ (3.3 million gallons) per well while those in the Marcellus required approximately $21,000 \mathrm{~m}^{3}$ (5.6 million gallons) per well [11]. Wells in the Permian Basin in west Texas generate significant volumes of WW while wells in the Marcellus/Utica region generate much lower WW volumes. In addition, WW in the Bakken shale in North Dakota has upwards of $200,000 \mathrm{mg} / \mathrm{L}$ of total dissolved solid (TDS) concentration while the wells in the Eagle Ford shale in southern Texas generate cleaner WW with approximately 40,000 mg/L TDS concentration [12, 13]. These differences in water use, WW quantity, and quality are important because they play a central role, along with other factors, in helping operators determine how to handle their various waste streams. Key characteristics of each shale play are listed in Table 1.

\section{Data Acquisition and Methods}

The data were compiled and curated for each shale region mainly from state agency's oil and gas division websites and databases, and spot-checked with industry data when possible. To the authors' knowledge, the necessary data to perform an analysis resolved by each shale region had not been synthesized, curated, nor available in one centralized location prior to this work. This process proved challenging and tedious as there was little consistency in how data were presented or reported across different state agency websites. This inconsistency is due to the fact that many rules and regulations related to HF practices are mandated on a state level. As such, each state implements their reporting requirements differently and some states do not currently require operators to report some information. For example, at the time of this study, Pennsylvania did not publish flared gas volumes directly. Instead, emissions due to natural gas operations are provided as an annual value broken down by source [20]. At the time of this study, only 2012 and 2013 emissions data were available in Pennsylvania. By comparison, Colorado published monthly FG volumes by county while North Dakota listed statewide FG volumes but did not separate the data by county $[22,23]$. North Dakota did, however, identify FG volumes for the Bakken region, specifically. Similar types of inconsistencies existed for both well completion and produced water volumes data across the various states.

Twelve states were considered for this analysis, spanning the seven shale plays of interest, since many plays cross state lines. In addition, where possible, data over multiple years, for 2012 through 2014, were obtained to see if any trends could be observed over the three-year period. 
Table 1 Summary of the key characteristics for the seven shale regions of interest

\begin{tabular}{|c|c|c|c|c|c|c|}
\hline Shale Region & $\begin{array}{l}\text { Predominantly } \\
\text { Oil or Gas Play }\end{array}$ & $\begin{array}{l}\text { PDSI index } \\
\text { Classification }\end{array}$ & $\begin{array}{c}\text { Wastewater } \\
\text { Volume }\end{array}$ & $\begin{array}{c}\text { Average TDS* } \\
\text { Concentration } \\
\text { (mg/L) }\end{array}$ & $\begin{array}{c}\text { Flared Gas } \\
\text { Volumes }\end{array}$ & $\begin{array}{c}\text { Sufficient } \\
\text { Nearby } \\
\text { Disposal }\end{array}$ \\
\hline Bakken & Oil & Slightly Wet & Low & 250,000 & Very High & Yes \\
\hline Marcellus/Utica & Gas & $\begin{array}{l}\text { Near Normal- } \\
\text { Slightly Wet }\end{array}$ & Very Low & 130,000 & Medium & No \\
\hline Eagle Ford & Oil \& Gas & Insipient Dry Spell & Medium & 40,000 & High & Yes \\
\hline Niobrara & Oil \& Gas & $\begin{array}{c}\text { Mild to Moderate } \\
\text { Drought }\end{array}$ & Very Low & 25,000 & Low & Yes \\
\hline Haynesville & Gas & Near Normal & Low & 120,000 & Low & Yes \\
\hline Permian Basin & Oil \& Gas & Insipient Dry Spell & Very High & 140,000 & Medium & Yes \\
\hline
\end{tabular}

Red indicates the characteristic is unfavorable for potentially coupling WW treatment with FG energy. Conversely, green indicates that the characteristic is relatively favorable for implementing the strategy. The Palmer Drought Severity Index (PDSI) was used to describe the general water availability in a region and takes into consideration precipitation and temperature, among other factors $[14,15]$. Despite the relatively low concentration of TDS in the Haynesville, treatment and reuse might remain a challenge due to other chemical constituents in the WW [11]. Quantitative descriptions of volumes of WW and FG are provided in the Results and Discussion section

*TDS: Total Dissolved Solids. The TDS concentration is used as one representation for the HF WW quality; average values were obtained from literature $[12,13,16-21]$

Preferably, data on the volume of WW generated, quality of the WW, and volume of FG would be available on a perwell basis with a daily, or even hourly, time resolution. Such data would likely make it possible to understand if enough FG was available for WW treatment on a near real-time basis and the level of treatment required based on the initial WW quality. Where data are available, the time resolution was often at best monthly. In addition, available data often do not clearly identify the source location of the FG as compared to the source location of the WW. This absence means that there is uncertainty regarding whether the primary sources of FG are coincident with the primary sources of WW. As a result of the low spatial resolution, we aggregated the volumes of WW and FG for each respective shale region. However, the data herein is still more finely resolved than state-level aggregations that have been reported in prior work [24].

\section{Curation Process}

Several significant complications with data acquisition were encountered including the following: (1) not all states require operators to report the data of interest; (2) some states do not separate their well information based on formation; (3) many state agency websites do not have limited online resources allowing for data to be downloaded and aggregated; (4) the data are sometimes labeled vaguely, leaving room for interpretation on their meaning; and (5) the data available are not always complete.
Table 2 provides a summary of data availability for each state of interest. The data collected and curated for this study were as follows: (1) the number of wells completed, (2) the volume of water used for HF, (3) the volume of WW generated, and (4) the volume of FG for each region. Where data are listed as "not found" or "not currently tracked," multiple attempts were made to obtain data by contacting the appropriate state agencies. In addition, subject matter experts were also contacted to provide additional clarification when the labeling of reported data was deemed vague. In limited cases, we were given state data that were not easily available online (e.g., data from Ohio and Louisiana). In other cases, the state agency confirmed that the desired data were unavailable or open record requests would be required to access the relevant documents. The following states were excluded from this study due to lack of available and accessible data or low well completion count in the relevant shale plays: Montana, West Virginia, Ohio, Wyoming, Nebraska, Kansas, Louisiana, and New Mexico.

All states included in this study require HF operators to disclose their chemical use which often means that the operators also disclose water volumes for HF. All but two of the states (Wyoming and New Mexico) require operators to report this information to FracFocus, a website to which operators report the makeup of fluid injected, location, and volume of water injected for each well.

Data for the Marcellus and the Utica shale formations were combined and considered as one region. Data for these formations were united because the states agencies of interest, primarily Pennsylvania, do not separate the WW or FG data by the formation from which they originated. 
Table 2 This table shows whether the relevant data (including number of wells completed, volume of water used for well completion, volume of WW generated, and volume of FG) were available for the regions of interest

\begin{tabular}{|c|c|c|c|c|c|c|}
\hline Shale Region & $\begin{array}{l}\text { Associated } \\
\text { States }\end{array}$ & Year & $\begin{array}{l}\text { Number of } \\
\text { completed } \\
\text { wells }\end{array}$ & $\begin{array}{l}\text { Water } \\
\text { Injected } \\
\text { Volume }\end{array}$ & $\begin{array}{c}\text { Wastewater } \\
\text { Volume }\end{array}$ & $\begin{array}{c}\text { Flared Gas } \\
\text { Volume }\end{array}$ \\
\hline \multirow{2}{*}{ Bakken } & North Dakota & $\begin{array}{l}2012 \\
2013 \\
2014\end{array}$ & 0 & $\begin{array}{l}0 \\
0 \\
0\end{array}$ & ? & 0 \\
\hline & Montana & $\begin{array}{l}2012 \\
2013 \\
2014\end{array}$ & $\begin{array}{l}\Delta \\
\Delta\end{array}$ & 0 & 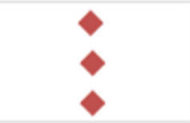 & $\begin{array}{l}\Delta \\
\Delta\end{array}$ \\
\hline \multirow{3}{*}{ Marcellus \& Utica } & Pennsylvania & $\begin{array}{l}2012 \\
2013 \\
2014\end{array}$ & $\begin{array}{l}0 \\
0 \\
0\end{array}$ & 0 & $\begin{array}{l}0 \\
0 \\
0\end{array}$ & ? \\
\hline & Ohio & $\begin{array}{l}2012 \\
2013 \\
2014\end{array}$ & $\begin{array}{l}0 \\
0 \\
0\end{array}$ & 0 & $\begin{array}{l}0 \\
0 \\
0\end{array}$ & $\dot{\varphi}$ \\
\hline & West Virginia & $\begin{array}{l}2012 \\
2013 \\
2014\end{array}$ & 0 & 0 & $\varphi$ & $\varphi$ \\
\hline \multirow[t]{5}{*}{ Eagle Ford } & Texas & $\begin{array}{l}2012 \\
2013 \\
2014\end{array}$ & 0 & 0 & 0 & 0 \\
\hline & Colorado & $\begin{array}{l}2012 \\
2013 \\
2014\end{array}$ & $\begin{array}{l}0 \\
\Delta\end{array}$ & 0 & 0 & 0 \\
\hline & Wyoming & $\begin{array}{l}2012 \\
2013 \\
2014\end{array}$ & ? & 0 & $\begin{array}{l}0 \\
0 \\
0\end{array}$ & $\begin{array}{l}0 \\
0 \\
0\end{array}$ \\
\hline & Nebraska & $\begin{array}{l}2012 \\
2013 \\
2014\end{array}$ & $\begin{array}{l}0 \\
0 \\
0\end{array}$ & $\begin{array}{l}0 \\
0 \\
0\end{array}$ & $\begin{array}{l}0 \\
0 \\
0\end{array}$ & 0 \\
\hline & Kansas & $\begin{array}{l}2012 \\
2013 \\
2014\end{array}$ & $\dot{v}$ & $\begin{array}{l}0 \\
0 \\
0\end{array}$ & 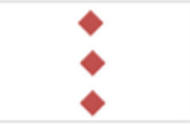 & $\dot{1}$ \\
\hline \multirow{2}{*}{ Haynesville } & Texas & $\begin{array}{l}2012 \\
2013 \\
2014\end{array}$ & $\begin{array}{l}0 \\
0 \\
0\end{array}$ & $\begin{array}{l}0 \\
0 \\
0\end{array}$ & $\begin{array}{l}0 \\
0 \\
0\end{array}$ & $\begin{array}{l}0 \\
0 \\
0\end{array}$ \\
\hline & Louisiana & $\begin{array}{l}2012 \\
2013 \\
2014\end{array}$ & $\begin{array}{l}0 \\
0 \\
0\end{array}$ & $\begin{array}{l}0 \\
0 \\
0\end{array}$ & $\begin{array}{l}\mathbf{0} \\
\mathbf{a} \\
\mathbf{a}\end{array}$ & $\begin{array}{l}\mathbf{B} \\
\mathbf{a} \\
\mathbf{a}\end{array}$ \\
\hline \multirow{2}{*}{ Permian Basin } & Texas & $\begin{array}{l}2012 \\
2013 \\
2014\end{array}$ & 0 & 0 & $\begin{array}{l}0 \\
0 \\
0\end{array}$ & 0 \\
\hline & New Mexico & $\begin{array}{l}2012 \\
2013 \\
2014 \\
\end{array}$ & 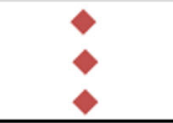 & 0 & $\begin{array}{l}\Delta \\
\Delta \\
\Delta\end{array}$ & 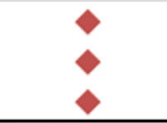 \\
\hline
\end{tabular}

\footnotetext{
Data found

Data are incomplete (e.g. state agency tracks but is backlogged so value is not most up-to-date/accurate, state collects but doesn't separate by formation) No data were found or not currently tracked

Data collected but not made easily accessible (e.g. on microfilm in state agency office, not online)
}

Data for the Marcellus and Utica shale plays were combined since some states do not differentiate their reported data based on shale formation 
While the WW quality is not central to this study, it plays a key role for understanding the possible treatment options that are technically feasible and whether treatment should even be considered. The WW often has a variety of constituents including dissolved solids, suspended solids, oils, and naturally occurring radioactive material (NORM), among many others. In some regions, the WW quality is so poor that treatment is likely unrealistic from an economic standpoint given currently available treatment options. The dirtier the WW, the lower the recovery rate (the fraction of TW compared to initial WW volume). Thus, as WW quality decreases so does the economic viability of WW treatment.

To the authors' knowledge, no states required detailed reporting of the WW quality. Therefore, we used the concentration of TDS in the WW as a proxy for WW quality. TDS concentration was used because removal of dissolved constituents via tertiary treatment technologies is often the most energy intensive step during WW treatment [25]. As a result, the TDS concentration is often the driving factor for how much energy must be expended to treat the WW. Other constituents should also be accounted for when fully defining the quality of a given water sample. The average TDS concentrations used to guide this study are provided in Table 1.

\section{Wastewater Treatment Options}

There are many potential WW treatment technologies. From a technical standpoint, choosing the appropriate technologies depends primarily on the WW quality and quantity and the desired use for the TW (i.e., the desired quality of the TW). Several treatment steps are often required to remove the various constituents present in WW [25]. Some of these steps are presented in Fig. 2. This study focused on the treatment technologies capable of reducing the TDS concentration. Specifically, mechanical vapor recompression (MVR) was chosen as the benchmark technology to conduct this engineering assessment for several reasons, including the following: (1) it is a technology that can treat high TDS concentrations common with HF WW, (2) the resulting high quality TW (effluent) affords the operators many options for beneficial reuse, (3) it is currently used for WW treatment at oil and gas sites suggesting that it has sufficient technical maturity, and (4) based on interviews with multiple industry experts, it appears to be the current industry standard when treating high salinity oil and gas WW to achieve high quality effluent [26]. However, there are many technologies under development and so it is likely that in the coming decades, new treatment approaches will be implemented. While MVR and other distillation techniques are often preceded by primary treatment steps such as chemical precipitation and coarse filtration, the energy intensity of these steps are not included in this analysis as they are often much lower by comparison [25-27]. As such, the energy intensity of MVR serves as a benchmark in this study to assess the amount of energy that would be required to treat the volume of WW in each region Figure 3.

\section{Analytical Methods}

The energy density of the FG is not constant due to the regional variability in natural gas composition across shale formations. For example, the natural gas produced in the Bakken has a higher energy density compared to other regions due to the higher percentage of natural gas liquids (NGL) such as ethane, butane, and propane [28]. The total primary energy in the FG is

$E_{\mathrm{FG}}[M J]=38.3\left[\frac{M J}{m^{3} \text { of natgas }}\right] \times \rho_{\mathrm{ED}} \times V_{\mathrm{FG}}\left[m^{3}\right]$

where $V_{\mathrm{FG}}$ is the volume of FG and $\rho_{\mathrm{ED}}$ is an energy density normalization factor that relates the actual energy density of the gas to the U.S. pipeline standard. For the purpose of this analysis, $\rho_{\mathrm{ED}}$ was set to unity, reflecting an assumption that the $\mathrm{FG}$ is pipeline quality natural gas and contains approximately $38.3 \mathrm{MJ} / \mathrm{m}^{3}$ (1028 $\left.\mathrm{BTU} / \mathrm{ft}^{3}\right)$ [29]. FG containing high fractions of inert gases would have a lower energy density and, in such cases, $\rho_{\mathrm{ED}}$ should be reduced below unity. While this work uses unity for illustrative purposes, future work could use the same analytical expression to consider a wider range of values for the energy density of FG.

The recovery rate (i.e., fraction of TW to total WW generated), estimated and listed in Table 3, varies by region and depends on the TDS concentration of the WW. For all regions, we assumed that MVR removes essentially all of the TDS concentration from the TW and generates a concentrated brine of $265,000 \mathrm{mg} / \mathrm{L}$ TDS (approximately 10-lb brine). The volume of treated water in a region is described as

$V_{\mathrm{TW}}\left[m^{3}\right]=F_{\text {recovery }} \times V_{\mathrm{WW}}\left[m^{3}\right]$

a function of the expected recovery rate for the region, $F_{\text {recovery, }}$ and the total wastewater volume in that region, $V_{\mathrm{WW}}$.

The amount of equivalent primary energy required to generate TW using MVR is

$E_{\mathrm{TW}}[M J]=\frac{e_{\mathrm{MVR}}\left[\frac{M J}{m^{3}}\right] \times V_{\mathrm{TW}}\left[m^{3}\right]}{\eta}$

a function of $V_{\mathrm{TW}}$, the energy intensity of MVR, $e_{\mathrm{MVR}}$, and the efficiency of the generator, $\eta$. This analysis incorporates a 


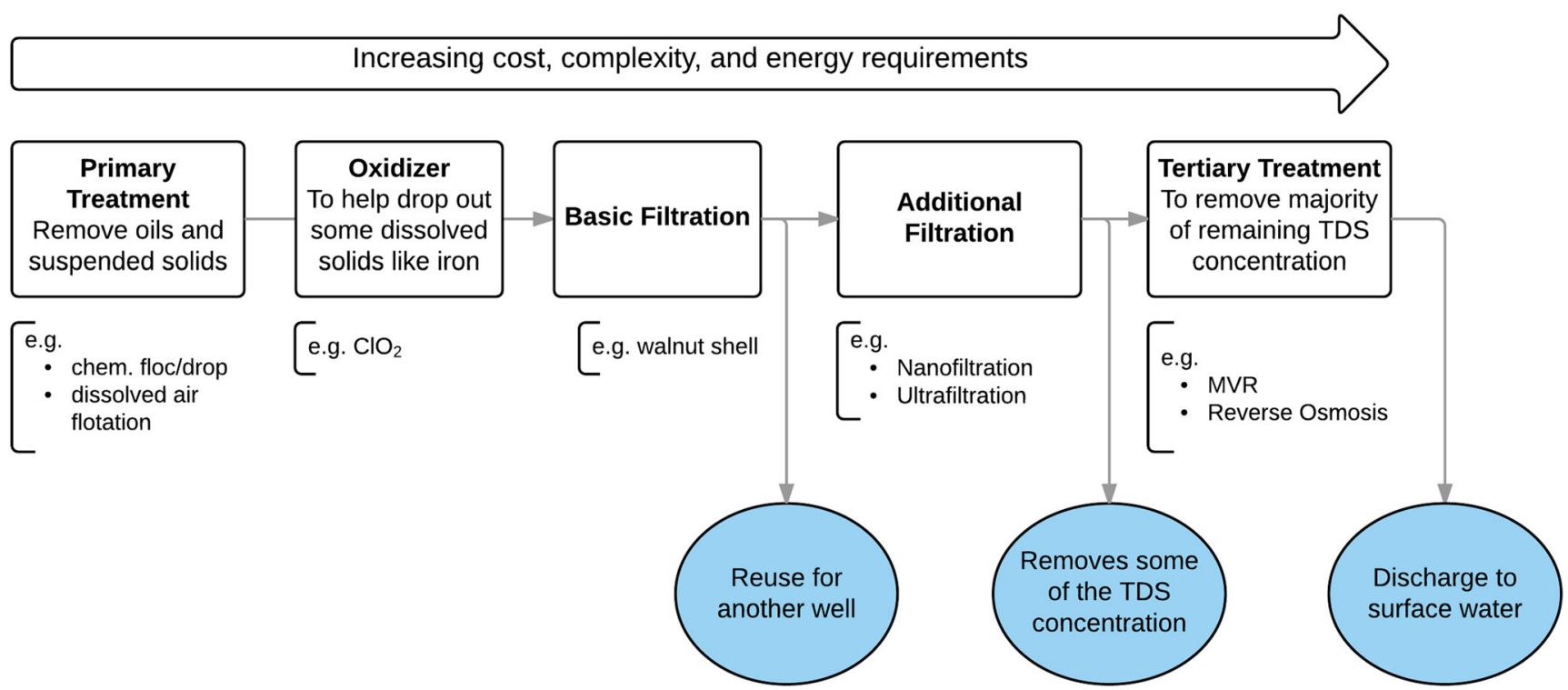

Fig. 2 An introduction to some of the treatment steps required to clean WW. Additional steps result in increasing cost, complexity, and energy requirements

model of an on-site reciprocating engine generator with a thermal efficiency of $\eta=35 \%$ to produce the electricity for driving the compressor. An energy intensity of $148 \mathrm{MJ} / \mathrm{m}^{3}$ (530 BTU/gal) of TW is used as an estimation for the MVR process based on available data from literature and interviews with existing operators of MVR units [27, 30]. Additional parasitic losses, such as pressure drop in system pipelines, were not included in this analysis.
The energy surplus ratio, $E_{\mathrm{FG}} / E_{\mathrm{TW}}$, was calculated for each region for each year (where data were available) and is included in Table 3. This ratio helps reveal the magnitude of wasted FG energy compared to the energy requirements for treatment. If the energy surplus ratio is less than one, there would not be enough energy in the aggregated FG to treat all of the WW in the region, in which case additional energy resources (from grid-tied electricity or extracted oil and gas, for example)

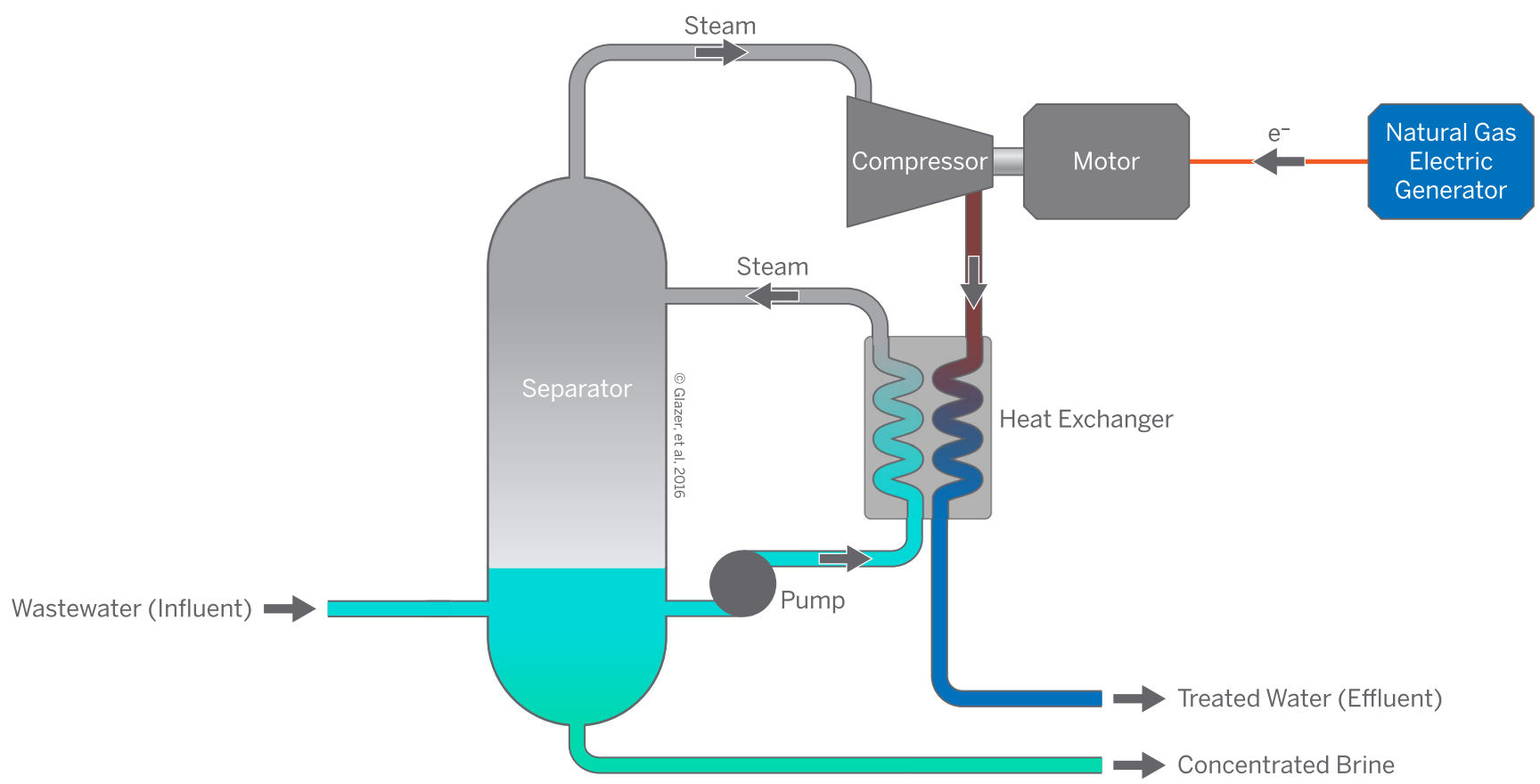

Fig. 3 A process diagram for a generic MVR system. Any water treatment technology will generate at least two outputs after treating wastewater: (1) TW that can be reused for beneficial purposes and (2) a concentrated waste stream that requires disposal or other forms of management. Under certain operating conditions, the treatment system can produce other valuable products such as concentrated salts for deicing roads or a $10-\mathrm{lb}$ brine that can be used for completing maintenance on wells. This system is powered by an electric motor 
Table 3 Summary of (1) the curated data including number of completed wells, WW, and FG volumes, (2) the estimated recovery rates for MVR, and (3) the calculated values for $E_{\mathrm{FG}}$ and $E_{\mathrm{TW}}$, and the ratio $E_{\mathrm{FG}} / E_{\mathrm{TW}}$ for the seven shale regions for 2012 through 2014 . Data were not available for 2014 in Pennsylvania at the time of this study

\begin{tabular}{|c|c|c|c|c|c|c|c|c|c|c|}
\hline Shale Region & $\begin{array}{l}\text { Associated } \\
\text { States }\end{array}$ & Year & $\begin{array}{c}\text { Number of } \\
\text { Completed } \\
\text { Wells }\end{array}$ & $\begin{array}{c}\text { Total Volume } \\
\text { of WW } \\
\left(10^{6} \mathrm{~m}^{3}\right)\end{array}$ & $\begin{array}{c}\text { Total } \\
\text { Volume of } \\
\text { FG } \\
\left(10^{6} \mathrm{~m}^{3}\right)\end{array}$ & $\begin{array}{c}\text { Recovery } \\
\text { Rate of } \\
\text { MVR (\%) }\end{array}$ & $\begin{array}{c}\text { Energy } \\
\text { of } F G \\
(P J)\end{array}$ & $\begin{array}{l}\text { Energy } \\
\text { Required for } \\
\text { WW Treatment } \\
\text { (PJ) }\end{array}$ & $\begin{array}{c}\text { Enough FG } \\
\text { for WW } \\
\text { Treatment? }\end{array}$ & $\begin{array}{c}\text { Ratio: Energy of } \\
\text { FG to Energy } \\
\text { Required for } \\
\text { WW Treatment }\end{array}$ \\
\hline Notation & & & & $V_{F G}$ & $V_{T W}$ & $F_{\text {recovery }}$ & $\overline{E_{F G}}$ & $E_{T W}$ & & $E_{F G} / E_{T W}$ \\
\hline \multirow{3}{*}{ Bakken } & & 2012 & 2010 & 4 & 2,120 & \multirow{3}{*}{10} & 81 & 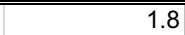 & Tes & $\begin{array}{ll}45.0 \\
\end{array}$ \\
\hline & North Dakota & 2013 & 2183 & 51.6 & 2,730 & & 105 & 2.2 & Yes & 47.7 \\
\hline & & 2014 & 2353 & 64.9 & 3,380 & & 129 & 2.7 & Yes & 47.8 \\
\hline \multirow{3}{*}{ Marcellus/Utica } & & 2012 & 2373 & 4.5 & 570 & \multirow{3}{*}{50} & 22 & 0.9 & Yes & 24.4 \\
\hline & Pennsylvania & 2013 & 2174 & 5.5 & 449 & & 17 & 1.2 & Yes & 14.2 \\
\hline & & 2014 & 2164 & 6.9 & $\mathrm{NF}$ & & N/A & N/A & $N / A$ & $\mathrm{~N} / \mathrm{A}$ \\
\hline \multirow{3}{*}{ Eagle Ford } & & 2012 & 4053 & 240.4 & 542 & \multirow{3}{*}{85} & 21 & 86 & No & 0.2 \\
\hline & Texas & 2013 & 6258 & 252.6 & 1,060 & & 41 & 91 & No & 0.5 \\
\hline & & 2014 & 6379 & 258.3 & 1,100 & & 42 & 93 & No & 0.5 \\
\hline \multirow{3}{*}{ Niobrara } & & 2012 & 2751 & 2.9 & 147 & \multirow{3}{*}{90} & 6 & 1.1 & Yes & 5.1 \\
\hline & Colorado & 2013 & 591 & 3.3 & 160 & & 6 & 1.2 & Yes & 5.1 \\
\hline & & 2014 & 80 & 5.2 & 102 & & 4 & 2.0 & Yes & 2.0 \\
\hline \multirow{3}{*}{ Haynesville } & & 2012 & 633 & 50.6 & 15 & \multirow{3}{*}{55} & 0.6 & 12 & No & 0.1 \\
\hline & Texas & 2013 & 523 & 48.0 & 17 & & 0.7 & 11 & No & 0.1 \\
\hline & & 2014 & 465 & 53.2 & 5 & & 0.2 & 12 & No & 0.0 \\
\hline \multirow{3}{*}{ Permian Basin } & & 2012 & 6602 & 660.2 & 233 & \multirow{3}{*}{50} & 9 & 140 & No & 0.1 \\
\hline & Texas & 2013 & 3677 & 686.4 & 621 & & 24 & 140 & No & 0.2 \\
\hline & & 2014 & 8415 & 752.0 & 925 & & 35 & 160 & No & 0.2 \\
\hline
\end{tabular}

would be necessary for WW treatment. A ratio of greater or equal to one suggests that there would be enough energy in the FG alone to treat all of the WW generated in the region.

\section{Results and Discussion}

The curated data for WW and FG volumes, the calculated values for $E_{\mathrm{FG}}$ and $E_{\mathrm{TW}}$, and the energy surplus ratio for each region are summarized in Table 3. Using the approach and assumptions noted above, the results reveal that from 2012 to 2014 the Bakken, Marcellus/Utica, and Niobrara shale regions had significantly more FG energy than would be required to treat the generated WW in the respective regions. In other words, the volume of FG might be considered a bigger environmental challenge than WW volumes in these regions. By contrast, Haynesville and Permian Basin had ratios much lower than one. The Eagle Ford had a ratio of approximately 0.5 in 2013 and 2014.

In Fig. 4a, the energy in the FG and primary energy required for WW treatment are shown for each region, along with the energy surplus ratio. Figure $4 \mathrm{~b}$ shows the volume of generated WW and volume of TW that could have been generated had the FG energy been used for WW treatment by region. The TW recovery rate depends heavily on the WW quality, specifically the TDS concentration. As such, the recovery rate is also included in the figure.

The US map in Figure 5 shows the energy surplus ratios, $E_{\mathrm{FG}} / E_{\mathrm{TW}}$ for 2014 by shale region. This map highlights the regions that from a technical stand point appear to have had a surplus of energy in the FG compared to the amount of energy required to treat the WW. Table 3 along with Figs. 4 and 5 reveals that FG was the dominant waste stream in the Bakken, Marcellus/Utica, and Niobrara regions during the years 2012 through 2014. By contrast, WW was the dominant waste stream in shale plays in Texas including the Eagle Ford, Permian Basin, and Haynesville.

\section{Regions Where $E_{\mathrm{FG}} / E_{\mathrm{TW}}$ Is Greater Than One}

\section{Marcellus/Utica}

The Marcellus/Utica, a mostly gas-producing region, appears to have flared far more energy than would be needed for treatment of the generated WW. This high $E_{\mathrm{FG}} / E_{\mathrm{TW}}$ ratio could be attributed to the fact that the volumes of WW were low for this region. The Marcellus/Utica region also has few SWD sites, which means WW requiring disposal must be trucked long distances, resulting in a logistical scenario that might favor on-site treatment of WW. The WW in Marcellus/Utica averages approximately $130,000 \mathrm{mg} / \mathrm{L}$ TDS, low enough that technologies like MVR are effective in treating the water [25, 27]. In fact, some operators are already treating their WW on-site [30].

\section{Bakken}

Approximately 45 times the amount of energy required for WW treatment was flared in the Bakken during 2012-2014. However, the extremely dirty WW with TDS concentrations upwards of $200,000 \mathrm{mg} / \mathrm{L}$ make treatment to freshwater standards unlikely [13]. While WW treatment appears to be impractical in the Bakken due to the extremely challenging WW 
Fig. 4 (a) A graph that shows the primary energy of FG and primary energy required for WW treatment for the shale regions of interest in 2014. The data presented for Marcellus/Utica is from 2013, due to lack of data availability for 2014 at the time of this study. The energy surplus ratio, $E_{\mathrm{FG}} / E_{\mathrm{TW}}$, is also included for each of the regions. (b) This graph shows the volume of WW and the potential volume of TW that could have been generated if the FG energy had been applied to WW treatment for the shale regions in 2014. The recovery rate of MVR for each region is also included
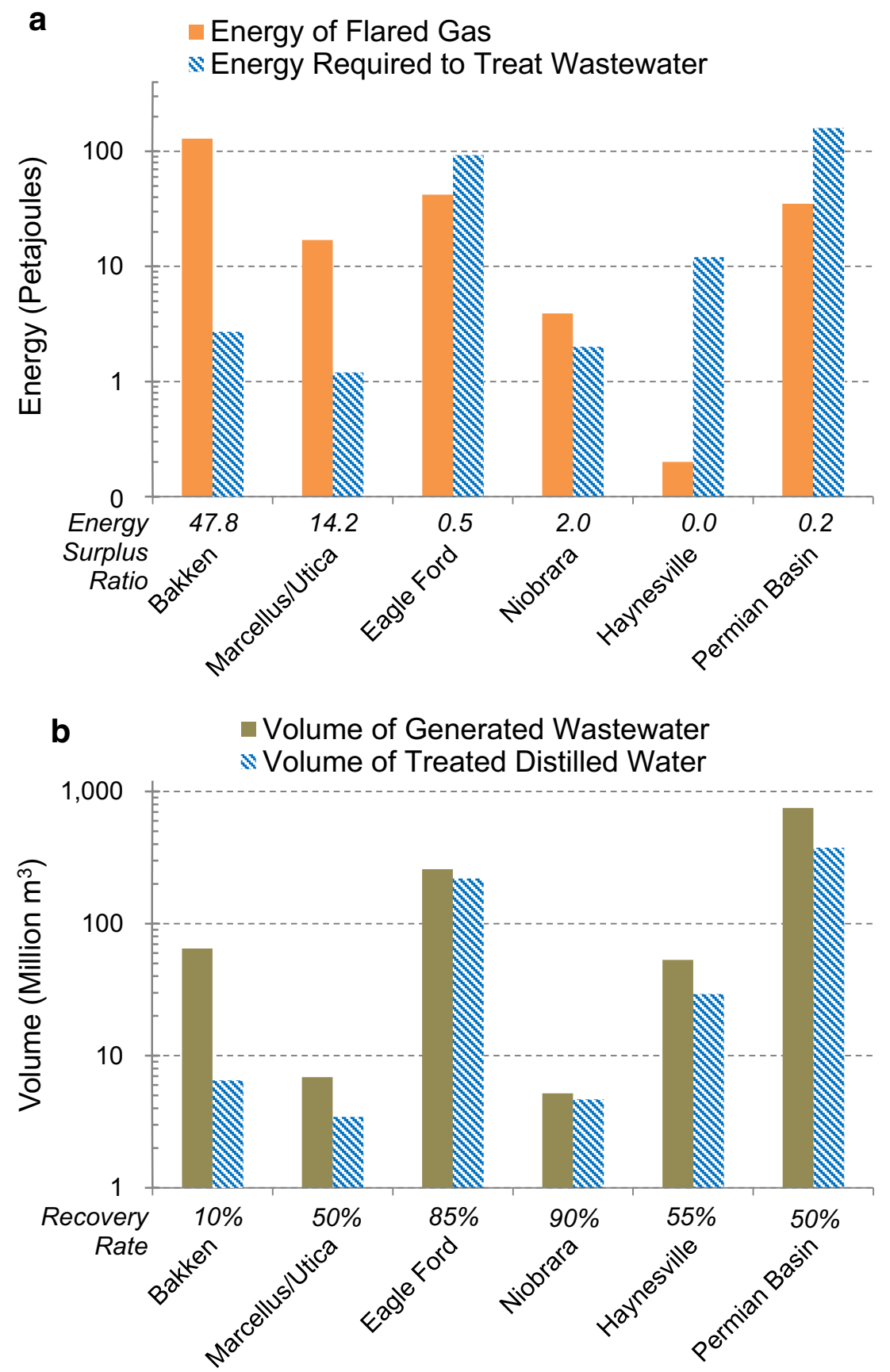

quality, the abundance of FG presents opportunities for other beneficial options such as replacing diesel generators with natural gas generators to supply on-site power.

In 2015 and the first half of 2016, the amount of FG in the Bakken decreased significantly in comparison to the 2014 data presented herein. In fact, the fraction of total gas production that is flared in North Dakota has declined from $36 \%$ in January 2014 to $10 \%$ as of March 2016 [31]. This decline in flaring can be attributed in part to the targets for reducing flaring that were set by the North Dakota Industrial Commission. In addition, the decline in oil prices around
2015 and subsequent decline in drilling operations in North Dakota has also likely impacted FG volumes in the Bakken.

\section{Niobrara}

While the FG energy was more than enough to treat the WW, aggregated volumes for both FG and WW were fairly low in the Niobrara as compared to most of the other regions considered in this study. The WW quality in the Niobrara is relatively conducive to treatment with MVR since typical WW TDS levels are approximately $25,000 \mathrm{mg} / \mathrm{L}$ [18]. In fact, this TDS level makes 


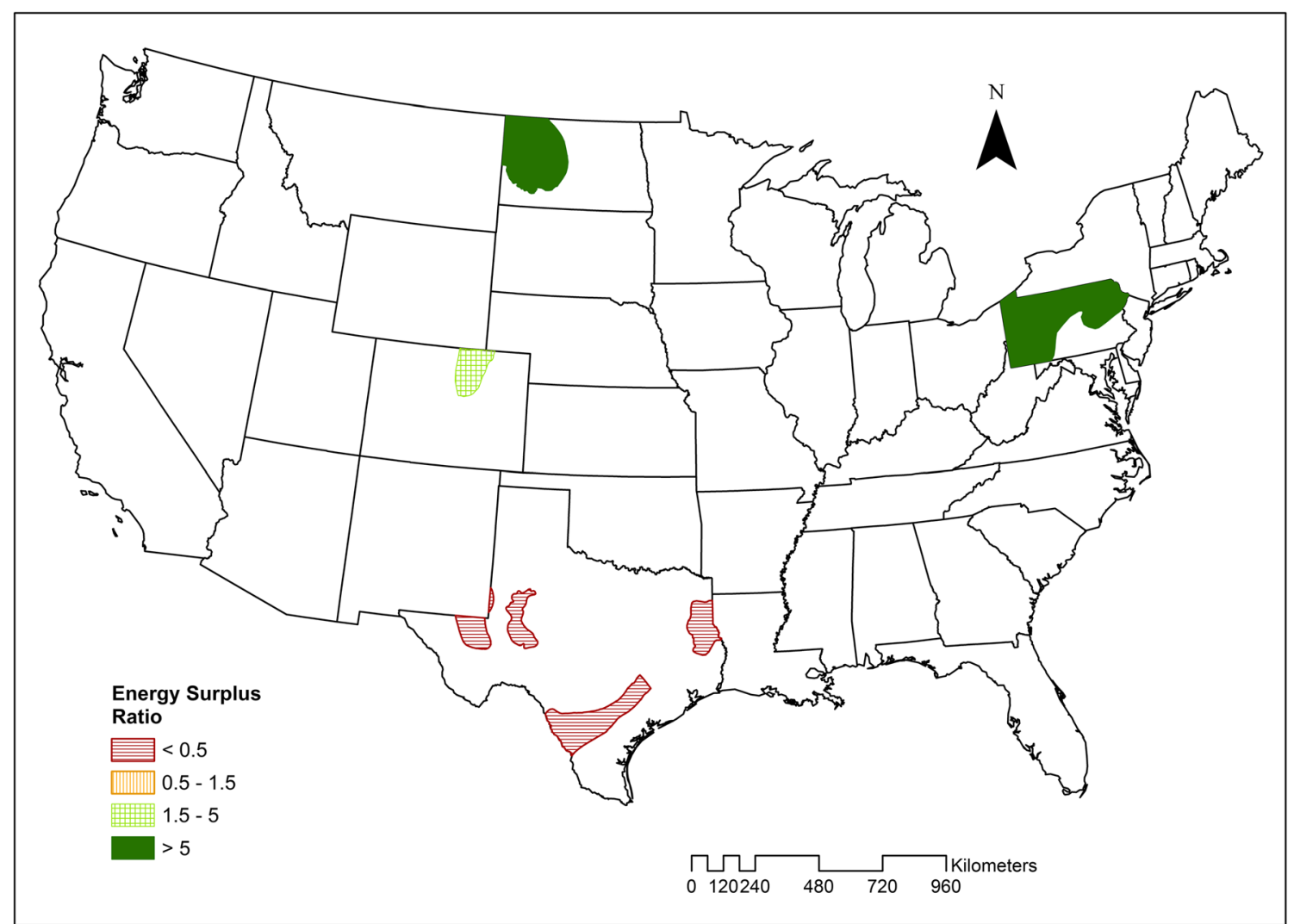

Fig. 5 Map showing the 2014 energy surplus ratios, $E_{\mathrm{FG}} / E_{\mathrm{TW}}$, for each region. The data presented for Marcellus/Utica are from 2013, due to lack of data availability in 2014 at the time of this study

Niobrara WW a candidate for treatment using reverse osmosis (RO). While RO is less energy intensive than MVR, detailed analysis of $\mathrm{RO}$ is beyond the scope of this paper.

\section{Regions Where $E_{\mathrm{FG}} / E_{\mathrm{TW}}$ Is Less Than One}

All three regions where there is insufficient FG energy to treat all the generated WW are in Texas, an area of the USA that has had significant oil and gas activity for many decades and, therefore, has built extensive gas gathering and WW disposal infrastructure. Consequently, these areas also have much greater access to non-flared energy sources (grid-tied electricity and marketed natural gas, for example) for managing wastewater.

\section{Permian Basin}

Approximately 752 million $\mathrm{m}^{3}$ (nearly 200 billion gallons) of WW was generated in the Permian Basin in 2014. This volume represented $66 \%$ of all the WW generated from the seven shale regions of interest. The Permian Basin is also arid, which means treating and reusing WW could be an important source of water for oil and gas operations in the region. In fact, some operators in the region are already reusing their treated WW [32]. As such, the practice of treating and reusing WW might grow because it helps mitigate challenges related to sourcing water in an arid environment. Relatively low FG volumes compared to the number of completed wells in the Permian Basin is likely due in part to the fact that the region has well established gas pipeline infrastructure that allows produced natural gas to be brought to market. Consequently, approximately $2 \%$ of the natural gas produced was flared in the region in 2014, which is much lower than in the Bakken shale [33]. To treat the WW generated in 2014, approximately $8 \%$ of the natural gas produced and sent to market in the region would have needed to be diverted to treatment. The region is also rich in renewable energy resources such as wind and solar. As such, rather than diverting natural gas, another approach could be to couple renewable resources with water treatment [34-37].

\section{Haynesville}

The Haynesville shale region had very low levels of FG and relatively low volumes of WW generated from 2012 through 2014. In addition, the WW is fairly poor quality in this region making treatment less attractive [11]. For these reasons, along 
with the fact that the Haynesville region has many SWD sites, WW treatment appears less viable compared to other regions considered in this study.

\section{Eagle Ford}

While the amount of FG energy is insufficient to treat all the generated WW, the FG could have provided approximately $50 \%$ of the regionally averaged energy requirements in the Eagle Ford in 2014. Other factors that make treatment in the region appealing are the low TDS concentrations, which average $40,000 \mathrm{mg} / \mathrm{L}$ TDS, and arid conditions that often leave the area water-stressed $[11,38]$.

\section{Conclusions}

The purpose of this study was to evaluate volumes of generated WW and FG associated with HF in the seven major shale regions in the USA. Understanding these volumes and their relative magnitudes in the various regions can help inform management and mitigation strategies for these waste streams. In addition, if the FG energy were repurposed for WW treatment, then two waste streams have the possibility of not only being reduced but also converted into a valuable commodity of TW. Aggregated volumes of FG and WW were curated from a variety of sources, primarily state and federal agencies. The treatment technology MVR was used as a benchmark along with engineering models to assess theoretical energy requirements for WW treatment and TW recovery rates.

This work shows that the Bakken, Marcellus/Utica, and Niobrara had sufficient energy from FG (on an aggregated basis across the region) to treat the WW that was produced from oil and gas operations in each respective region from 2012 through 2014. The available energy from aggregated FG in the Eagle Ford, Permian Basin, and Haynesville was sufficient to meet approximately 50,20, and $2 \%$ of the energy requirements for WW treatment in the regions in 2014, respectively, meaning that water management strategies such as treatment and re-use would require energy sources in addition to the FG.

The largest sources of FG and the region with the most WW are not aligned. The Bakken flared more than 3.3 billion $\mathrm{m}^{3}$ (117 billion cubic feet) of natural gas in 2014, approximately $57 \%$ of all the gas flared in the seven regions considered and approximately $41 \%$ of all flared and vented gas in the USA in 2014 [9]. The Permian Basin on the other hand produced approximately 752 million $\mathrm{m}^{3}$ (nearly 200 billion gallons) of WW in 2014, 66\% of all WW produced in the seven shale regions considered, but flared relatively little gas.

The proposed strategy should be considered on a well-bywell basis in future studies and within the prevailing regulatory context. While the prospect of using FG for WW treatment might not be aligned across the entire shale region, it might be well-matched for individual wells or drilling pads. Each well will have unique operating conditions such as the flow rates for FG and WW, the availability of local water resources, and the presence of pipeline and SWD infrastructure. These factors, among others, might make the proposed strategy appealing for certain wells. However, the logistical challenge of matching the temporal and spatial variations of WW and FG supply presents a challenge for implementation at many wells. As a result, the conclusions provided herein that detail which regions have sufficient aggregated FG to treat the WW serve as a first-order identification of regions where oil and gas operators might consider implementing the proposed strategy.

There are many critical aspects not discussed in this analysis including economic feasibility, logistical challenges, and impacts of regulatory changes on the overall landscape. While economic feasibility is key to understanding the potential of using FG for WW treatment, this type of economic analysis depends on first conducting a technical assessment as presented in this manuscript. A deeper analysis of economic feasibility is beyond the scope of the current study given the deep complexity required in performing a rigorous financial assessment on a site-specific basis but is part of our ongoing work where the capital and operational costs of the current practices are compared with a variety of waste stream mitigation approaches on a case-by-case basis.

It is currently unclear what a low-price oil environment will do for the prospects of WW treatment: on one hand operators will be looking for every opportunity to improve operational efficiency, on the other hand reduced capital spending will likely limit the growth of new hardware in the field. Regions with known water scarcity or limited WW disposal sites might be more inclined to treat and reuse WW. In addition, the volume of FG in each region will likely decrease as gas pipeline infrastructure catches up with the expansion in drilling operations that occurred during 2011-2015. Lastly, changes in regulations that impact current practices for sourcing HF water, changes that expand beneficial uses of WW, or new limits on allowable volumes of FG might encourage operators to consider new alternatives for how they manage both FG and WW. Future work will provide a detailed assessment of costs, logistics, and the impacts of regulations when considering whether it is feasible to use the energy from FG to power WW treatment.

Acknowledgements The authors would like to thank the United States Department of Energy, The Cynthia \& George Mitchell Foundation, the Texas State Energy Conservation Office, the Alfred P. Sloan Foundation, and Statoil for funding some elements of this research. In addition, the authors would like to thank Anthony Smith of X Chem; Ray Jones of 
Purestream Services; and Cecilie Nygaard, Desikan Sundararajan, and Andrea Miguens of Statoil for their intellectual contributions to this paper.

\section{Compliance with Ethical Standards}

Conflict of Interest Yael R. Glazer, F. Todd Davidson, and Jamie J. Lee each report a research grant from Statoil ASA to the University of Texas at Austin and Department of Energy, research grant to the University of Texas at Austin, and a research grant from Aethon Corporation to the University of Texas at Austin; and report consulting fees from Oilfield Water Logistics.

Michael E. Webber reports a research grant from Statoil ASA to the University of Texas at Austin and Department of Energy, research grant to the University of Texas at Austin; research grant from Aethon Corporation to the University of Texas at Austin; and reports consulting fees from Oilfield Water Logistics. Dr. Webber serves as the Editor-inChief of Current Sustainable/Renewable Energy Reports.

Human and Animal Rights and Informed Consent This article does not contain any studies with human or animal subjects performed by any of the authors.

Open Access This article is distributed under the terms of the Creative Commons Attribution 4.0 International License (http://creativecommons. org/licenses/by/4.0/), which permits unrestricted use, distribution, and reproduction in any medium, provided you give appropriate credit to the original author(s) and the source, provide a link to the Creative Commons license, and indicate if changes were made.

\section{References}

1. U.S. Energy information administration petroleum \& other liquids https://www.eia.gov/petroleum/production/\#oil-tab (accessed September 22, 2017), Monthly crude oil and natural gas production.

2. Vengosh A, Jackson RB, Warner N, Darrah TH, Kondash A. A critical review of the risks to water resources from unconventional shale gas development and hydraulic fracturing in the United States. Environ Sci Technol. 2014;48:8334-48.

3. Chen $\mathrm{H}$, Carter KE. Water usage for natural gas production through hydraulic fracturing in the United States from 2008 to 2014. J Environ Manag. 2016;170:152-9.

4. Glazer YR, Kjellsson JB, Sanders KT, Webber ME. Potential for using energy from flared gas for on-site hydraulic fracturing wastewater treatment in texas. Environ Sci Technol Lett. 2014;1(7):3004.

5. Drouin RR. As fracking booms, growing concerns about wastewater. Yale Environmental 360, 2014.

6. Deep injection wells: how drilling waste is disposed underground, StateImpact; https://stateimpact.npr.org/pennsylvania/tag/deepinjection-well/.

7. Mueller D. Recycling wastewater from oil and gas wells pose challenges. Environmental Defense Fund Energy Exchange, 2015.

8. North Dakota Industrial Commission Order 24665 Policy/ Guidance, Version 102215; https://www.dmr.nd.gov/oilgas/ GuidancePolicyNorthDakotaIndustrialCommissionorder24665. pdf (accessed September 22, 2017).

9. U.S. energy information administration natural gas. https://www. eia.gov/dnav/ng/ng_prod_sum_a_EPG0_VGV_mmcf_a.htm (accessed June 1, 2016), Natural gas gross withdrawals and production
10. Scanlon BR, Reedy RC, Nicot JP. Comparison of water use for hydraulic fracturing for unconventional oil and gas versus conventional oil Environ. Sci Technol. 2014;48:12386-93.

11. Mantell ME. Produced water reuse and recycling challenges and opportunities across major shale plays. Presented at the EPA hydraulic fracturing study technical workshop \#4: water resources management [Online], March 29-30, 2011. U.S. Environmental Protection Agency. http://www.epa.gov/hfstudy/produced-waterreuse-and-recycling-challenges-and-opportunities-across-majorshale-plays (Mar 9, 2016).

12. Ennenga T. Mechanical vapor recompression: a viable option for flowback and produced water reuse, Proceedings of the Shale Water EXPO, 2014.

13. Slutz J, Anderson J, Broderick R, Horner P. Key shale gas water management strategies: an economic assessment tool, Proceedings of the SPE/APPEA International Conference on Health, Safety, and Environment in Oil and Gas Exploration and Production, Perth, Australia, Sept 11-13, 2012.

14. National Drought Mitigation Center. How do I measure drought? $\mathrm{http} / /$ drought.unl.edu/ranchplan/DroughtBasics/WeatherDrought/ MeasuringDrought.aspx (accessed June 28, 2016).

15. National Centers for Environmental Information. Climate at a glance. http://www.ncdc.noaa.gov/cag/ (accessed June 28, 2016).

16. Zhou J, Baltazar M, Sun H, Qu Q. Water-based environmentally preferred friction reducer in ultrahigh-TDS produced water for slickwater fracturing in shale reservoirs, Proceedings of the SPE/ EAGE European Unconventional Conference and Exhibition, Vienna, Austria, Feb 25-27, 2014.

17. Silva JM, Matis H, Kostedt WL, Watkins V. Produced water pretreatment for water recovery and salt production, Technical Report for RPSEA Contract 08122-36; Research partnership to secure energy for America: Niskayuna, NY, Jan 2012.

18. Coday BD, Almaraz N, Cath TY. Forward osmosis desalination of oil and gas wastewater: impacts of membrane selection and operating conditions on process performance. J Membr Sci. 2015;488:4055 .

19. McLaughlin JB. Key considerations for Frac flowback/produced water reuse and treatment. Presented at NYWEA Spring Technical Conference, Syracuse, NY, June 4, 2013.

20. PA DEP oil \& gas reporting website; https://www. paoilandgasreporting.state.pa.us/publicreports/Modules/Welcome/ Agreement.aspx.

21. Hancock N. High salinity produced water treatment made economically viable, In Water Recycling and Desalination for the Oil and Gas Industry, Proceedings of International Desalination Association, May 12-14, 2013.

22. Colorado Oil And Gas Information System (COGIS), Colorado Oil \& Gas Conservation Commission, 2014; http://cogcc.state.co.us/.

23. North Dakota drilling and production statistics, official portal for North Dakota State Government; https:/www.dmr.nd.gov/oilgas/ stats/statisticsvw.asp.

24. Veil J. U.S. Produced water volumes and management practices. Prepared for the Ground Water Protection Council. April 2015

25. An integrated framework for treatment and management of produced water - technical assessment of produced water treatment technologies, Colorado School of Mines, 1st Edition, RPSEA Project 07122-12, November 2009.

26. Homer P, Halldorson B, Slutz J. Shale gas water treatment value chain-a review of technologies including case studies, Proceedings of the SPE Annual Technical Conference and Exhibition, Denver, Colorado, Oct 30-Nov 2, 2011.

27. Hayes T, Severin BF. Evaluation of the aqua pure mechanical vapor recompression system in the treatment of shale gas flowback water, Technical Report for RPSEA Contract 08122-05; Research Partnership to Secure Energy for America: Sugar Land, TX, March 2012. 
28. Salmon R, Logan A. Flaring up: North Dakota natural gas flaring more than doubles in two years; technical report for ceres: Boston, MA, July 2013.

29. Heat content of natural gas consumed, U.S. Energy Information Administration, 2015; http://www.eia.gov/dnav/ng/ng_cons_heat_ a_epg0_vgth_btucf_a.htm

30. Rahm BG, Bates JT, Bertoia LR, Galford AE, Yoxtheimer DA. Wastewater management and Marcellus shale gas development: trends, drivers, and planning implications. J Env Man. 2013;120: 105-13.

31. Davis N. Natural gas flaring in North Dakota has declined sharply since 2014. U.S. Energy Information Administration Today in Energy, June 13, 2016.

32. Lyons B, Tintera JJ. Sustainable water management in the texas oil and gas industry. Atlantic Council Energy \& Environment Program, July 2014, 1-24.

33. Texas Permian Basin total natural gas production 2008 through April 2016, 2016. Texas Railroad Commission. http://www.rrc. state.tx.us/media/21223/permianbasin_totalnaturalgas_perday.pdf (accessed June 28, 2016).
34. Glazer YR. The potential for using energy from flared gas or renewable resources for on-site hydraulic fracturing wastewater treatment. Master's Thesis, The University of Texas at Austin, May 2014.

35. Clayton ME, Stillwell AS, Webber ME. Implementation of brackish groundwater desalination using wind-generated electricity: a case study of the energy-water nexus in Texas. Sustainability. 2014;6:758-78.

36. Gold GM, Webber ME. The energy-water nexus: an analysis and comparison of various configurations integrating desalination with renewable power. Resources. 2015;4:227-76.

37. Kjellsson JB, Webber ME. The energy-water nexus: spatiallyresolved analysis of the potential for desalinating brackish groundwater by use of solar energy. Resources. 2015;4:476-89.

38. Nicot J, Scanlon BR. Water use for shale-gas production in Texas. US Environ Sci Technol. 2012;46:3580-6.

39. Drilling productivity report, 2016. U.S. Energy Information Administration. http://www.eia.gov/petroleum/drilling/pdf/dprfull.pdf (accessed June 28, 2016). 